\title{
Effectiveness of participatory learning activity (PLA) cum lecture method on knowledge of nursing students in HIV/AIDS
}

\author{
Neetha Kamath, Dr. N. Udayakiran \\ Ph D Student, Nitte University, Mangalore, \\ Professor and HOD Department of community medicine K S Hegde Medical academy, Nitte University \\ Mangalore, Karnataka, India
}

\begin{abstract}
:
Introduction: The present study aimed to determine the effectiveness of participatory learning activity cum Lecture method on knowledge of nursing students regarding HIV/AIDS.

Materials and methods: An evaluative approach with pre experimental one group pre-test post-test design was adopted with the sample of 200 I year nursing students selectedbyconvenientsamplingtechnique studying in different nursing institutions of Dakshina Kannada district.

Results: Effectiveness of teaching method was done by comparing the difference in the mean pre test and post tests knowledge score. The calculated ' $t$ ' value $(t=47.57)$ was greater than the table value $\left(t_{199}=1.96\right)$ at 0.001 level of significance. This shows that there is significant difference in pre-test and post-test knowledge score.
\end{abstract}

Conclusion: The study results show that PLA cum Lecture method is an effective teaching method. The Nurse educators can incorporate these teaching methods in classroom and clinical setting.

Key words: Participatory learning Activity cum Lecture method. Effectiveness, Knowledge, Nursing students

\section{Introduction:}

Education is a light that shows the mankind the right direction to surge. The purpose of education is not just making a student literate but adds rationale thinking, knowledgeable and self sufficiency. When there is a willingness to change, there is hope for progress in any field. Creativity can be developed and innovation benefits both students and teachers ${ }^{1}$.

Nursing education principally concentrates on transmitting nursing knowledge, and assisting nursing students to acquire the necessary skills and attitudes associated with nursing practice. To meet the diverse needs of today's educational climate, nursing educators must develop an understanding of a variety of learning environments and skills in contemporary teaching strategies. Nurses must also maintain the ability of divergent thinking to solve the health problems of patients. One way to enhance nursing education is to determine the effect of teaching methods on nursing student's achievements and teaching effectiveness at nursing colleges ${ }^{2}$.

The studies support the positive effect of delivering nursing education through active learning techniques and innovative teaching strategies on student's achievements and thinking abilities. Delivering nursing education through the traditional lecture format, on the other hand, is criticized for its emphasis on the learners' passive receipt of knowledge rather than learning to think critically (Alexander et al., 2002; Biley, 1998). Moreover, in nursing education the interest in improving student's achievements and the quality of teaching effectiveness have been increased over the time ${ }^{3}$. The purpose of this research study was to determine the effect of participatory learning cum lecture method on knowledge in HIV/AIDS among nursing students.

\section{Statement of the Research Problem}

Effectiveness of participatory learning activity (PLA) cum lecture method in teaching on HIV/AIDS among nursing students of selected institutions in Dakshina Kannada

\section{Objectives:}

- To determine the pretest knowledge regarding HIV/AIDS among nursing students

- To find the effectiveness of participatory learning activity (PLA) cum lecture method in teaching on HIV/AIDS among nursing students.

- To find association between pretest knowledge level of nursing students and selected demographic variables.

Hypothesis: (all hypotheses will be tested at 0.05 level of significance) 
$\mathbf{H}_{1}$ : The mean post test knowledge score on HIV/AIDS after PLA cum lecture will be significantly higher than their mean pre test knowledge score among nursing students

$\mathbf{H}_{2}$ : There will be association between the pre test knowledge level and selected demographic variables of nursing students

\section{Methodology:}

An evaluative approach with pre experimental one group pre-test post-test design was adopted in ordertoachievetheobjectivesofthestudy.Thesamples of 200 I year nursing students were selectedbyconvenientsamplingtechnique.The studywasconductedin different nursing institutions of Dakshina Kannada district. Theindependentvariableinthisstudywas use of Participatory learning activity method cum lecture method to teach nursing students regarding HIV/AIDS $\begin{array}{ccccc}\text {.Assessment } & \text { of } & \text { Howledge } & \text { HIDS }\end{array}$ the dependentvariable.TheconceptualframeworkofthestudywasbasedontheImogeneKingsGoal

attainmentmodel(1981). The investigator proceeded the present study on basis of assumptions such as a) Students who undergo participatory learning method are goal directed individuals who take initiation in learning process. b) Learning method influence an individual preference to learning situation.

The researcher used the structured knowledge questionnaire on HIV/AIDS to assesstheknowledgelevelof nursing students.Thedevelopmentof the tool involvedthesteps ofitemconstruction,i.e.preparingtheblueprint,itemwriting, item analysis, and content validity, pre-testing andestablishingreliability. The items which were having difficulty index between 40-70\%and discrimination index between 0.25 and above were included in the questionnaire. The content validityof the developedtool was established by seven experts opinion and suggestionsin the field of community health nursing and education. The reliabilityof thetool was established using split half method and foundtobe0.83. The investigator prepared the lesson plan to conduct the session on HIV/AIDS using PLA cum lecture method ${ }^{4}$. This also was validated by the experts. The lesson plan content on HIV/AIDS included following heading such as Introduction, epidemiology, Incidence, mode of transmission, clinical features, management and prevention.

\section{Data collection method:}

Ethical clearance certificate was obtained from Ethical committee of Nitte University prior to the data collection. Formal administrative permission was obtained from the principals of nursing colleges. Thepilotstudy wasconductedwith 30samplesofnursing college of Mangalore. The experience of the pilot study was found to be feasible and practicable. Themainstudywasconductedwith $200 \quad$ I year nursing students whowereselectedusingconvenientsamplingtechnique.Theselectedsubjectswereinformed ofthe purpose of the study and consent was obtained. The knowledge regarding HIV was assessed by administering Knowledge questionnaire. The students had taken 45 minutes to answer all the items in questionnaire.

The investigator delivered teaching using participatory learning cum lecture method. The different PLA methods used to teach the students were group discussion, Timeline, concept mapping, body mapping, skill matrix and role play and then lecture method. For each session the investigator had selected 35-40 students and the duration of session was $3 \mathrm{hrs}$. Post-testwas conducted using the same questionnaire on the seventhday to find the effectivenessofteaching methodoncomponentsof HIV/AIDS. The collected data was entered in master data sheet for analysis. The data was analysed using descriptive and inferential statistics using SPSS package.

\section{Descriptive analysis}

\section{Results:}

The demographic characteristics of nursing students were analysed using descriptive statistics such as frequency and percentage. Majority $179(89.5 \%)$ of the subjects were females. With regard to religion, 171 $(85.9 \%)$ of were Christians. Majority of $187(93.5 \%)$ of subject were belonging to nuclear family. Regarding current residence of the subjects173(86.5\%) of subjects were residing in hostel. All the participants had prior knowledge of HIV/AIDS and 173(86.5\%) of subjects received the information on HIV through T.V/Radio.

Knowledge score of nursing students regarding HIV/AIDS were arbitrarily graded into grades like good, average and poor .In pre test $60.5 \%$ of subjects had poor Knowledge level, $35.5 \%$ of subjects had Average and only $4 \%$ of subjects had good knowledge level whereas in post test $100 \%$ of subjects had goodknowledge. 
Table 1: Mean, median, mean percentage, actual gain and modified gain of area wise pre and post test knowledge score of nursing students regarding HIV/AIDS

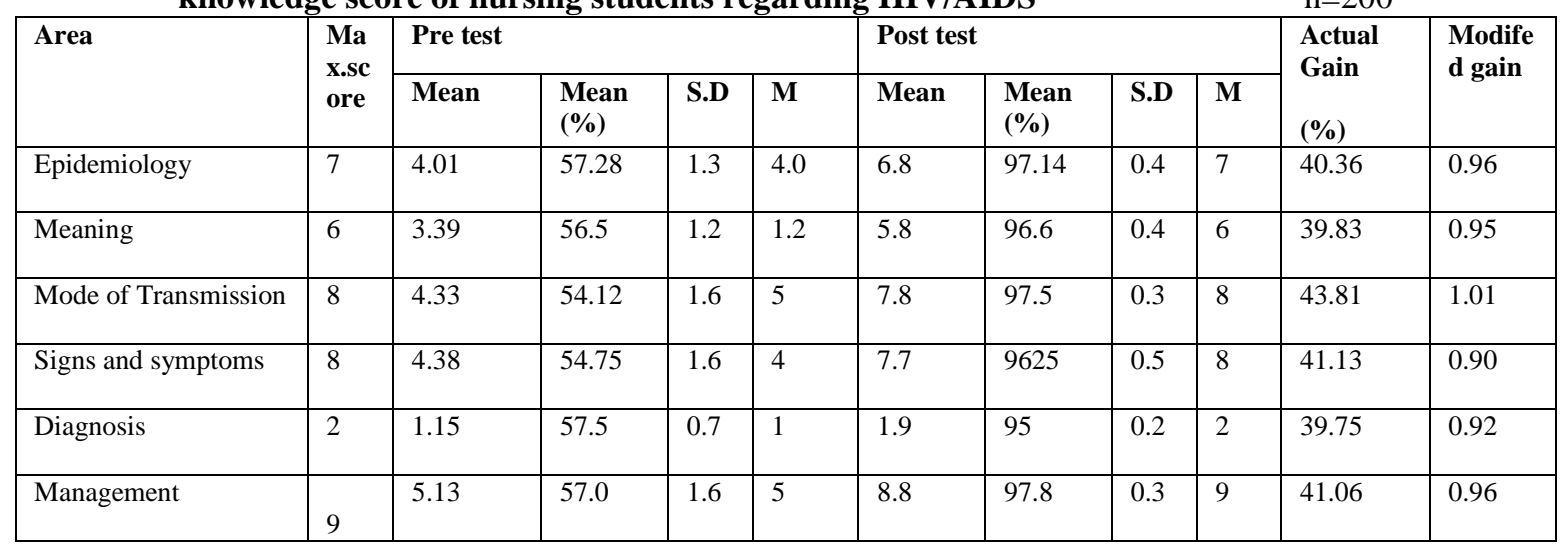

According to the Table 1 the area wise percentage of actual gain between pre and posttest knowledge score was found to be $40.36 \%$ increase and modified gain 0.96 in epidemiology of HIV,39.83 \% increase and modified gain0.95 in area of meaning, $43.81 \%$ increase and modified gain1.01 in the area of mode of transmission, $41.13 \%$ increase and modified gain 0.90 in the area of signs and symptoms,39.75\% increase and modified gain0.92 in the area of diagnosis and $41.06 \%$ increase and modified gain0.96 in the area of management of HIV.

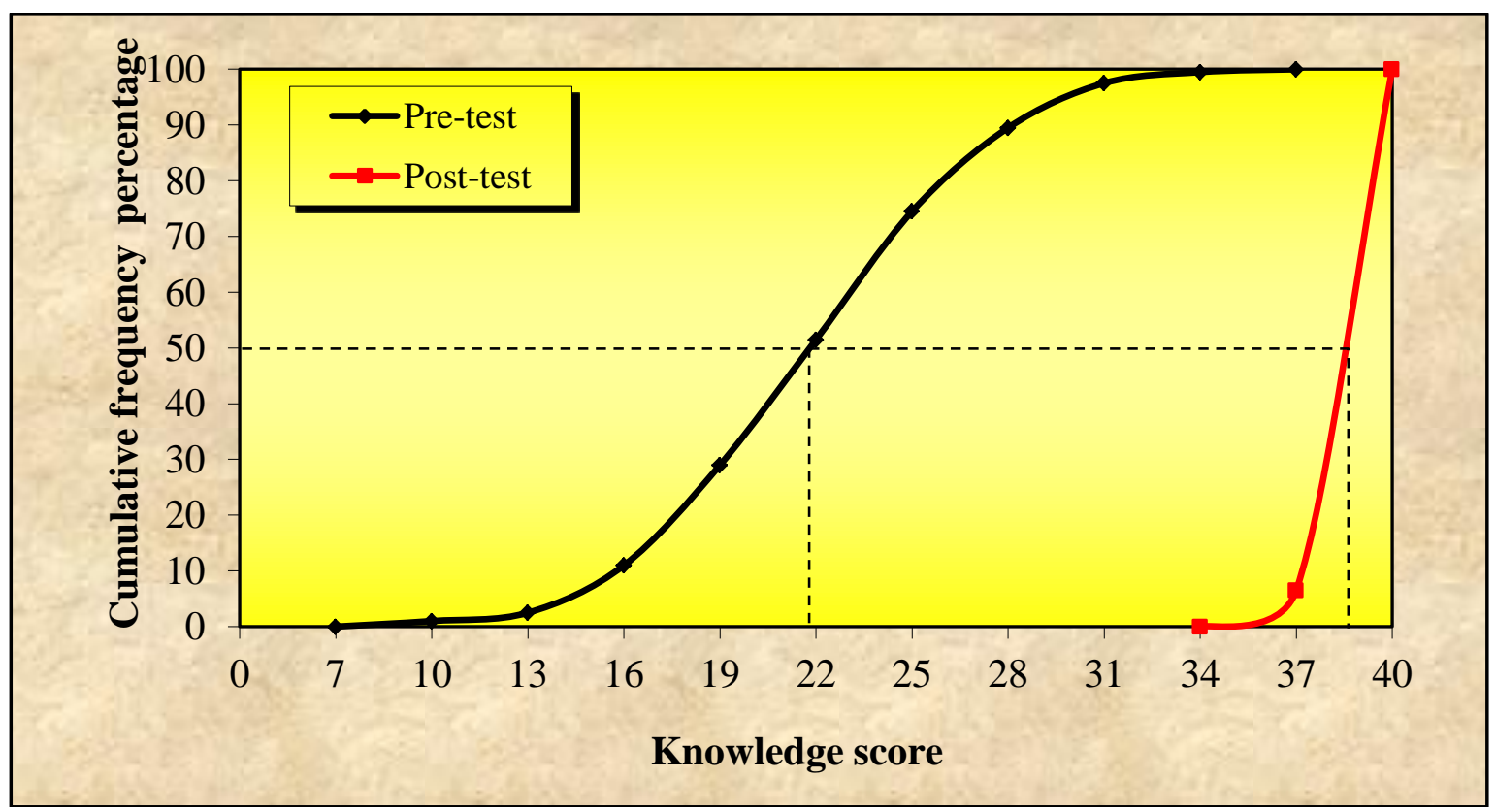

Figure 1 :Ogive representing pre test- post test knowledge score of nursing students on HIV/AIDS

DatainFigure1showsthatthepost-testogiveliestotherightofthepre-testOgiveover the entire range ,showing that the post-test knowledge score was consistently higher than the pre-test knowledge score. Difference in achievement betweenpreandposttestknowledgescorewasshownbydistanceseparatingthetwocumulativefrequencycurves,

whichisatthe $50^{\text {th }}$ percentile anditrangeswithitsmedianfrom22to39, whichindicatesthatmostofthe nursing s t u d e n t s securedincreasedscoreinthepost-testthanthepre-test.

Inferential analysis:

Effectiveness of teaching method was done by comparing the difference in mean pre test and post tests knowledge score 
Table 2: Mean, SD and Paired t test showing the effectiveness of PLA cum lecture methodamong nursing students regarding HIV/AIDS

\begin{tabular}{|c|c|c|c|c|c|c|c|}
\hline & & & & & & $=200$ & \\
\hline \multirow[t]{2}{*}{ Variable } & \multicolumn{2}{|l|}{ Mean } & \multirow[t]{2}{*}{ Mean difference } & \multicolumn{2}{|l|}{ SD } & \multirow[t]{2}{*}{ t value } & \multirow[t]{2}{*}{ df } \\
\hline & Pretest & Posttest & & Pretest & posttest & & \\
\hline Knowledge score & 22.39 & 39.0 & 16.50 & 5.6 & 1.5 & $47.57^{*}$ & 199 \\
\hline
\end{tabular}

Data in Table 2 shows that the mean post test knowledge score(39.0) was higher than the mean pre test score(22.39). The calculated ' $t$ ' value $(t=47.57)$ is greater than the table value $\left(t_{199}=1.96\right)$ at 0.001 level of significance. This shows that there is significant difference in pre-test and post-test knowledge score. Therefore PLA cum lecture method is an effective teaching method.

The association between the pre test knowledge level and demographic variables of nursing students is analyzed using Chi-square test. The finding show pre test knowledge level and calculated $\mathrm{X}^{2}$ value of gender $\left(\mathrm{X}^{2}\right.$ $=0.230>\mathrm{P}=0.631)$ religion $(\mathrm{P}=0.719)$, type of family $(\mathrm{P}=0.474)$, current resident $(\mathrm{P}=0.486)$, and source of information $(\mathrm{P}=0.668)$ was lesser than the table $\mathrm{X}^{2}$ value. This shows that the association between pre test knowledge level and demographic variables was not statistically significant at 0.05 levels.

\section{Discussion:}

The results of the present study show that PLA cum lecture method is an effective method of teaching, but lecture method if taught with PLA methods would be highly effective teaching method. The present study results are congruent with the study conducted inMaharastraon effect of Participatory learning and lecture learning method on outcome based education in nursing. This indicate that participatory learning is effective strategy in build upon the interests of the students and individualize their classroom experience integral to this programme ${ }^{4}$.The study results are in line with another study to compare the effectiveness of 3 modes of teaching, namely, traditional classroom lecture, E-learning, and a combination of E-learning and traditional classroom lectures. The second aim was to examine factors associated with the retention of knowledge in asthma management and the learning preference of Nurses. There were no significant differences in retention of knowledge among the 3 modes of teaching. However, there seems to be an increase in preference for the combination mode of teaching $(\mathrm{EL}+\mathrm{TCL})$ as compared with either method alone ${ }^{5}$.

\section{Conclusion;}

The results of the present study concluded that students exposed to the participatory cum lecture method show better outcome. What seem evident from the results of this current study was that PLA and Lecture has a greater potential for effective communication of HIV/AIDS in the classroom. This was important because the PLA cum Lecture offers the learners as individuals and together in groups, the unique opportunity to read, accept and internalize the basic concepts. It is therefore, possible for the nursing students to work, within this approach, at their own pace, master the subject as indicated by the accuracy of their own responses and eventually carry such knowledge and experience to their various groups for the benefits of the other group members. The approach equally allows nursing students' knowledge of immediate feedback which serves as a great motivation propelling students to learn more.

\section{Reference:}

[1]. Damodaran V S, Rangarajan V. Innovative teaching methods. International journal of nursing education. 2011;8(3): 65-8

[2]. Salsali M. Evaluating teaching effectiveness in nursing education: An Iranian perspective. BMC Medical Education. 2005; 3(3): $5: 29$.

[3]. Rahmani A, Mohajjel-Aghdam A, Fathi-Azar E, Abdullahzadeh F. Comparing the effects of Concept Mapping and Integration method on nursing students' learning in nursing process course in Tabriz University of Medical Sciences. Iranian Journal of Medical Education. 2007; 7(1):41-9.

[4]. Radha V, Chandeker P A. Effect of engaged learning upon lecture learning method on Outcome Based Education in Nursing - An experimental study. IOSR journal of research method in education. 2013;2(3) 7-11

[5]. Prabhakaran L, Chee J, Earnest A, Salleh S. Comparison of three modes of teaching enrolled nurses on asthma management. Journal of Asthma \& Allergy Educators .2012; 3(3):117-126.

[6]. PolitFD,BeckTC.Nursingresearchprinciplesandmethods. $8^{\text {th }}$ edn.New Delhi:WoltersKluwerPvt. Ltd.;2008.

[7]. KothariCR.Researchmethodology,methodsandtechniques. $2^{\text {nde d }}$.New Delhi:NewAgeInternationalPublications;2004 